\title{
Silencing of phosphoglucose isomerase/autocrine motility factor decreases U87 human glioblastoma cell migration
}

\author{
YANG LI, ZHENQING WEI, BIN DONG, ZHIGANG LIAN and YINGHUI XU
}

Department of Neurosurgery, The First Affiliated Hospital of Dalian Medical University, Dalian, Liaoning 116011, P.R. China

Received June 19, 2015; Accepted February 3, 2016

DOI: $10.3892 / \mathrm{ijmm} .2016 .2500$

\begin{abstract}
Phosphoglucose isomerase/autocrine motility factor (PGI/AMF) is secreted by tumors and influences tumor growth and metastasis. In order to investigate the effects of silencing PGI/AMF on the migration and the sphere forming abilities of human glioblastoma U87 cells, as well as on the side population cells (SPCs), PGI/AMF was silenced using siRNA. Western blot analysis and RT-qPCR were used to assess the expression of PGI/AMF, Akt and SRY (sex determining region $\mathrm{Y}$ )-box 2 (SOX2). Wound healing, migration and tumorsphere formation assays were performed to assess invasion and metastatic potential. The proportion of SPCs was determined using Hoechst 33342 dye and flow cytometric analysis. PGI/AMF silencing inhibited the wound healing capacity and migration ability of U87 cells by 52.6 and $80.4 \%$, respectively, compared with the scrambled siRNA (both $\mathrm{P}<0.001)$. Silencing of $\mathrm{PGI} / \mathrm{AMF}$ decreased the proportion of SPCs in the U87 cells by $80.9 \%(\mathrm{P}<0.01)$. The silencing of PGI/AMF decreased the number and size of tumorspheres by 53.1 and $39.9 \%$, respectively, compared with the scrambled siRNA (both $\mathrm{P}<0.01$ ). The silencing of PGI/AMF decreased the levels of phosphorylated Akt $(-71.9 \%, \mathrm{P}<0.001)$ compared with the scrambled siRNA, as well as the levels of the stemness marker, SOX2 (-61.7\%, P<0.01). Taken together, these findings suggest that PGI/AMF silencing decreases migration, tumorsphere formation as well as the proportion of SPCs in glioblastoma U87 cells. We suggest that the Akt pathway is involved, and our results provide a potential new target for the treatment of glioblastoma.
\end{abstract}

\section{Introduction}

A glioblastoma is a tumor of the central nervous system and the most malignant of all astrocytic tumors, and it is associated with a poor prognosis (1). Glioblastomas represent $25 \%$ of all

Correspondence to: Dr Yinghui Xu, Department of Neurosurgery, The First Affiliated Hospital of Dalian Medical University, No. 222 Zhongshan Road, Dalian, Liaoning 116011, P.R. China

E-mail: yinhuixudl@126.com

Key words: glioblastoma, side population cells, phosphoglucose isomerase/autocrine motility factor, tumor growth, metastasis malignant nervous system tumors, with an annual incidence of $3 / 100,000$ individuals in the United States, and of $<2 / 100,000$ individuals in Europe (1). Exposure to radiation, second-hand tobacco smoke and rare hereditary disorders are associated with an increased risk of glioblastoma $(1,2)$. The tumor consists of poorly differentiated, neoplastic astrocytes with a diffuse infiltration pattern, making surgery difficult (3). Deletion of annexin A7 (ANXA7) is found in $75 \%$ of cases (4). Genetic changes and loss of heterozygosity, epidermal growth factor receptor (EGFR), p16, tumor protein 53 (TP53) and phosphatase and tensin homolog (PTEN) are often observed (1). Survival rates are very low, with $<30 \%$ at 1 year and $3 \%$ at 5 years $(1,5)$. Currently available treatments have a limited efficacy: a clinical trial using radiation therapy and temozolomide reported a 5-year survival rate of $9.8 \%$ (6).

It has previously been shown that phosphoglucose isomerase/autocrine motility factor (PGI/AMF) is important for cell migration in high-grade glioma (7). $\mathrm{AMF} /$ neuroleukin (NLK)/maturation factor (MF) is an extracellular phosphohexose isomerase (PHI) that is secreted by malignant cells (8-10). AMF acts in a cytokine-like manner through the AMF receptor (AMFR), also known as $78 \mathrm{kDa}$ glycoprotein (gp78), which is a seven-transmembrane domain glycoprotein (11). AMF stimulates tumor angiogenesis $(12,13)$, ascites formation (14), apoptotic resistance (15-17), cell proliferation (17,18), matrix metalloproteinase-3 (MMP-3) secretion (19) and cell motility (12-14,20). All of these factors are associated with tumor aggressiveness, invasion and metastatic spread. It has been demonstrated that the mRNA expression of AMF is higher in glioblastomas compared with that in astrocytomas, and the overall survival of patients with AMF-positive glioblastoma is poorer than in patients with AMF-negative glioblastoma (7).

The aim of the present study was to elucidate the role that PGI/AMF plays in glioblastoma U87 cells by evaluating the effect of silencing PGI/AMF expression on migration and sphere forming ability of the cells, as well as on the side population cell (SPC) proportion. The results of the present study provide potential new targets for the treatment of glioblastoma.

\section{Materials and methods}

Cell culture. Human glioblastoma U87 cells were purchased from the Cell Bank of the Chinese Academy of Sciences (Shanghai, China) and were cultured in Dulbecco's modified Eagle's medium (DMEM) with 10\% heat-inactivated fetal 
bovine serum (FBS) (both from Gibco, Grand Island, NY, USA) and $1 \%$ penicillin $(100 \mathrm{U} / \mathrm{ml}) /$ streptomycin $(100 \mu \mathrm{g} / \mathrm{ml})$ at $37^{\circ} \mathrm{C}$ in an atmosphere with $5 \% \mathrm{CO}_{2}$.

RNA interference. Sequences of specific small interfering RNA (siRNA) targeting PGI/AMF were described previously (20). The target sequence for the PGI/AMF siRNA was 5'-UGG UAC CGC GAG CAC CGC UTT-3' modified with a 5'-FAM (carboxyfluorescein). The scrambled siRNA sequence used was 5'-ACG UGA CAC GUU CGG AGA ATT-3' (both from GenePharma Co., Ltd., Shanghai, China). Following $24 \mathrm{~h}$ of incubation, $50 \mathrm{nM}$ siRNA duplex transfection was undertaken, into U87 cells using Lipofectamine 2000 (BD Biosciences, San Jose, CA, USA), according to the manufacturer's instructions. The results were observed directly under the fluorescence microscope (DM2500 LED; Leica, Wetzlar, Germany) The efficiency of PGI/AMF silencing was analyzed after $24 \mathrm{~h}$ of transfection using reverse transcription-quantitative polymerase chain reaction (RT-qPCR) and western blot analysis.

Wound healing assay. The U87 cells transfected with PGI/AMF siRNA were seeded onto 24-well plates 3 days after transfection and were cultured to at least $95 \%$ confluence. Monolayer cells were washed with serum-free Dulbecco's modified Eagle's medium (DMEM) (Gibco) and then scraped with a plastic $200 \mu 1$ pipette tip and placed back in the incubator at $37^{\circ} \mathrm{C}$. Images of the wounded areas were captured using a CKX41 phase contrast microscope (Olympus, Tokyo, Japan) at two time points ( 0 and $8 \mathrm{~h}$ after scraping). Images were analyzed using Adobe Photoshop 7.0 software (Adobe Systems, Inc., San Jose, CA, USA). The relative migration distance was calculated using the following formula: relative migration distance $(\%)=(\mathrm{A}-\mathrm{B}) / \mathrm{A} \times 100 \%$, where $\mathrm{A}$ is the width of the wound $0 \mathrm{~h}$ after scraping, and $B$ is the width of the wound $8 \mathrm{~h}$ after scraping.

Migration assay. An in vitro migration assay was performed 3 days after transfection using Transwell cell culture chambers (no. 3422; Corning Inc., Corning, NY, USA). The cells were re-suspended in DMEM supplemented with 0.1\% FBS. The cell suspensions $\left(1 \times 10^{5}\right.$ cells) were added to the upper compartment of the chamber. The bottom chamber was filled with DMEM supplemented with 10\% FBS. After $8 \mathrm{~h}$ of incubation, the topside of the insert membrane was scrubbed with a cotton swab to remove the non-invasive cells and the bottom side was fixed with methanol and stained with $1 \%$ hematoxylin and eosin (H\&E). Migrating cells were counted under a CKX41 phase contrast microscope at a magnification of $\mathrm{x} 400$ within 10 randomly selected microscope fields.

SPC assay. The SPCs were assessed using previously published methods $(21,22)$. Briefly, three days after transfection, the U87 cell suspensions were labeled with Hoechst 33342 dye (Sigma-Aldrich, St. Louis, MO, USA). The U87 cells were resuspended at $1 \times 10^{6} / \mathrm{ml}$ in pre-warmed high-glucose DMEM with $2 \%$ FBS. Hoechst 33342 dye was added at a final concentration of $5 \mu \mathrm{g} / \mathrm{ml}$ in the presence or absence of reserpine (50 $\mu \mathrm{mol} / \mathrm{l})$ (Aladdin Chemicals Co., Ltd., Shanghai, China) as controls for the SPC gating, and the cells were incubated at $37^{\circ} \mathrm{C}$ for $90 \mathrm{~min}$ with intermittent shaking. At the end of the incubation, the cells were washed with ice-cold PBS with $2 \%$ FBS, centrifuged
(200 x g for $5 \mathrm{~min}$ ) at $4^{\circ} \mathrm{C}$, and resuspended in ice-cold Hank's Balanced Salt Solution (HBSS) containing 2\% FBS, in the dark. Analysis was undertaken using a FACSAria II flow cytometer (BD Biosciences). The Hoechst 33342 dye was excited at $357 \mathrm{~nm}$ and its fluorescence was analyzed by dual-wavelength measurements (blue, 402-446 nm; red, 650-670 nm).

Sphere formation assay. Three days after transfection, the U87 cells were diluted in serum-free growth medium $(1,000$ cells $/ \mathrm{ml})$ and plated $(100 \mu \mathrm{l})$ in 96 -well plates. The cells were cultured with serum-free growth medium for 14 days. The culture medium consisted of serum-free DMEM/F12 (Gibco, Invitrogen, Carlsbad, CA, USA) supplemented with $2 \%$ B27 (Invitrogen), human recombinant fibroblast growth factor 2 (FGF-2, $20 \mathrm{ng} / \mathrm{ml}$ ) and epidermal growth factor (EGF, $20 \mathrm{ng} / \mathrm{ml}$ ) (both from PeproTech, Rocky Hill, NJ, USA). After 14 days, the spheres were measured and those $>100 \mu \mathrm{m}$ were counted as tumorsphere-forming units. The data calculated for the number and size of the tumorspheres was the average of three independent experiments. The spheres were counted and measured from 32 different wells/experiment.

$R T-q P C R$. Twenty-four hours after transfection, total RNA was isolated from the U87 cells using TRIzol (Takara Bio, Otsu, Japan), according to the manufacturer's instructions. RNA purity was assessed by spectrophotometry $\left(\mathrm{OD}_{260} / \mathrm{OD}_{280 \mathrm{~nm}}\right)$. RNA was transcribed into cDNA using TIANScript M-MLV reverse transcriptase and the TIANScript RT kit (Tiangen Biotech (Beijing) Co., Ltd., Beijing, China). cDNA (5 $\mu \mathrm{l})$ was added to the 2X Taq PCR Master Mix system (Tiangen Biotech Co., Ltd.). For quantitative evaluation of the amplified product, 20-40 cycles of PCR were performed preliminarily to determine the most suitable number of amplifications for each reaction. PCR cycling conditions consisted of $30 \mathrm{sec}$ at $95^{\circ} \mathrm{C}$, $30 \mathrm{sec}$ at $55^{\circ} \mathrm{C}$, and $1 \mathrm{~min}$ at $72^{\circ} \mathrm{C}$ for PGI/AMF; and $30 \mathrm{sec}$ at $95^{\circ} \mathrm{C}, 30 \mathrm{sec}$ at $60^{\circ} \mathrm{C}$, and $1 \mathrm{~min}$ at $72^{\circ} \mathrm{C}$ for $\beta$-actin. PGI/AMF and $\beta$-actin were amplified using the following primers: PGI/ AMF forward, 5'-AAT GCA GAG ACG GCG AAG GAG-3' and reverse, 5'-ACG AGA AGA GAA AGG GGA GTC-3'; $\beta$-actin forward, 5'-TGG CAC CCA GCA CAA TGA A-3' and reverse, 5'-CTA AGT CAT AGT CCG CCT AGA AGC A-3'. Amplification of $\beta$-actin was used to estimate the efficiency of cDNA synthesis and to normalize PGI/AMF expression. The amplified products were separated on $1 \%$ agarose gel electrophoresis. The gel was stained with ethidium bromide and images were captured using a camera (Panasonic, Kadoma, Japan). The products were quantified by analyzing the band density using Quantity One V4.6.2 software (Bio-Rad, Hercules, CA, USA).

Protein extraction and western blot analysis. Twenty-four hours after transfection, the U87 cells were washed twice with PBS and lysed with $500 \mu \mathrm{l}$ cell lysis buffer for western blot analysis, supplemented with PMSF (both from Beyotime, Jiangsu, China). The supernatant from the lysate was collected after centrifugation $\left(12,500 \mathrm{x} \mathrm{g}\right.$ for $20 \mathrm{~min}$ at $\left.4^{\circ} \mathrm{C}\right)$. The cell supernatants were supplemented with PMSF and concentrated at over 100-fold with a centrifugal evaporator (CVE-200D; (Eyela, Tokyo, Japan), and the protein concentrations in the supernatant were determined using a BCA assay. Equal amounts of protein ( 40 or $50 \mu \mathrm{g})$ 

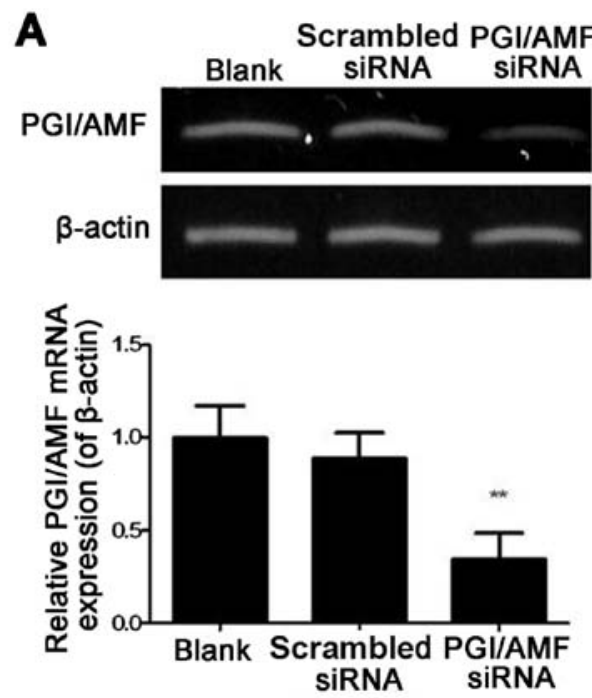
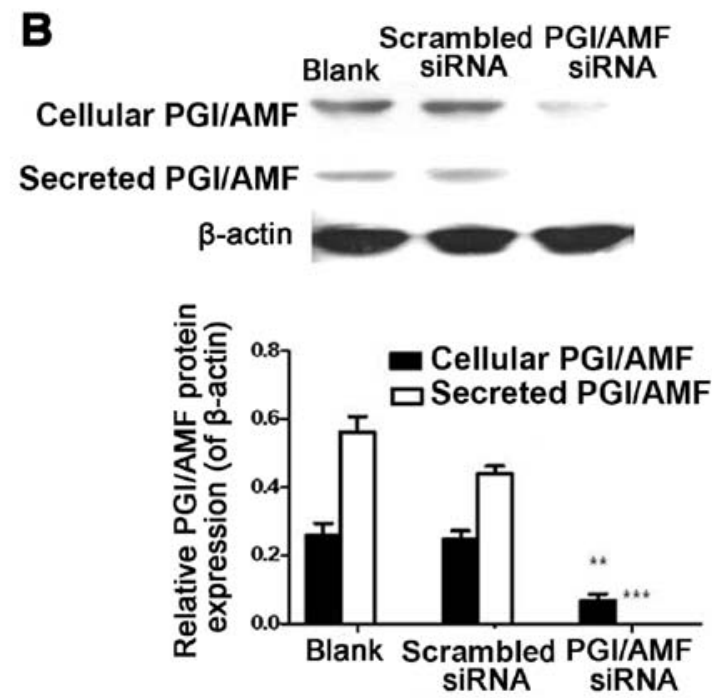
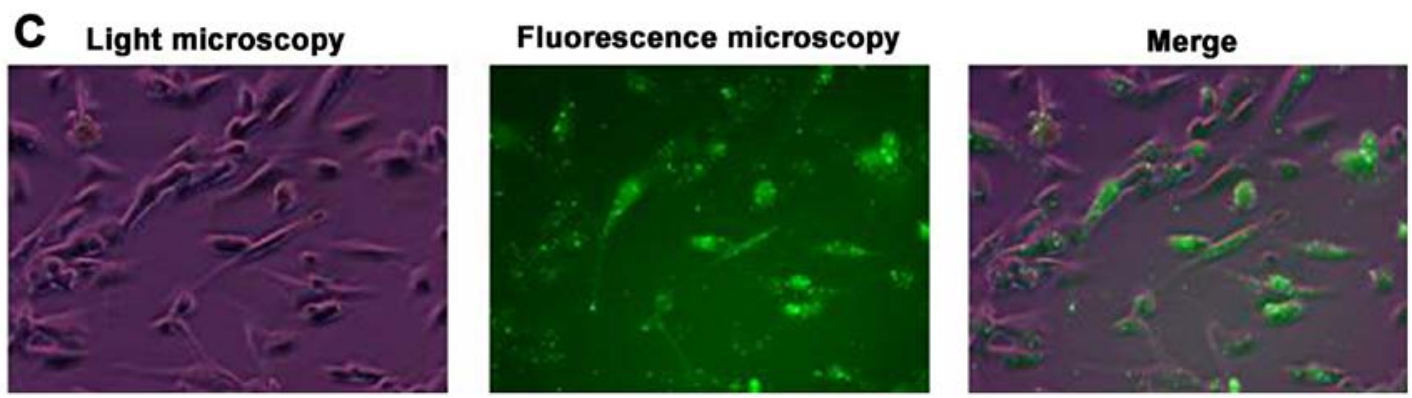

Figure 1. Phosphoglucose isomerase/autocrine motility factor (PGI/AMF) siRNA silencing in human glioblastoma U87 cells. The U87 cells were transfected with PGI/AMF siRNA or scrambled siRNA for $24 \mathrm{~h}$. (A) PGI/AMF mRNA expression was determined by RT-qPCR. (B) PGI/AMF protein expression in cells and supernatants was determined by western blot analysis. $\beta$-actin was used as an internal control. Data are represented as the means \pm standard deviation (SD) from three independent experiments. ${ }^{* *} \mathrm{P}<0.01$ and ${ }^{* * * *} \mathrm{P}<0.001 \mathrm{vs}$. scrambled siRNA. (C) Transfection efficiency was determined by fluorescence analysis. Left panel, light microscopy; middle panel, fluorescence microscopy; right panel, merge; green, FAM. Magnification, x400.

were subjected to $10 \%$ SDS-PAGE and transferred onto PVDF membranes (pore size, $0.45 \mu \mathrm{m}$ ) (Millipore, Billerica, MA, USA). The membranes were blocked with $5 \%$ non-fat skimmed milk in PBS for $1 \mathrm{~h}$ at room temperature and incubated with primary antibodies. The following antibodies were used for western blot analysis: rabbit anti-Akt (\#9272; 1:1,000) and rabbit antip-Akt (\#9271; 1:1,000; both from Cell Signaling Technology, Danvers, MA, USA), goat anti-PGI/AMF (sc-30392; 1:2,000; Santa Cruz Biotechnology, Inc., Santa Cruz, CA, USA), mouse anti-SRY (sex determining region Y)-box 2 (SOX2) (S1451; $1: 1,000$; Sigma-Aldrich) or mouse anti- $\beta$-actin (TA-09; $1: 1,000$; ZSGB-Bio, Beijing, China) overnight at $4^{\circ} \mathrm{C}$. The membranes were processed with horseradish peroxidase (HRP)-conjugated secondary antibodies [goat anti-mouse IgG (ZB-5305), ZSGB-Bio; goat anti-rabbit IgG (SA00001-2), Proteintech Group,Inc., Chicago,IL, USA; or donkey anti-goat IgG (sc-2020), Santa Cruz Biotechnology, Inc.]. Immunoreactive bands were visualized using enhanced chemiluminescence (ECL) western blotting detection reagents (P0018; Beyotime, Beijing, China). The blots were stripped and re-developed with $\beta$-actin antibody to normalize data. Immunodetection was followed by visualization using ECL, and densitometry using Quantity One V4.6.2 software (Bio-Rad).

Statistical analysis. Data for each group are represented as the means \pm standard deviation (SD) from three independent experiments. Data were evaluated using the unpaired t test and GraphPad Prism 5.0 (GraphPad Software Inc., San Diego, CA, USA). A two-sided P-value $<0.05$ was considered to indicate a statistically significant difference.

\section{Results}

Silencing of PGI/AMF in U87 cells. RT-qPCR and western blot analysis showed that PGI/AMF mRNA and protein expression levels in U87 cells were decreased by PGI/AMF siRNA (both $\mathrm{P}<0.01$ ) (Fig. 1). Of note, the silencing of endogenous PGI/AMF by siRNA led to the complete inhibition of PGI/AMF secretion (Fig. 1B). There was no statistical difference in mRNA and protein expression between the untreated cells and the cells transfected with scrambled siRNA (both $\mathrm{P}>0.05)$. Transfection efficiency, shown as GFP-positive cells, was observed under a fluorescence microscope (Fig. 1C).

Inhibition of wound healing capacity and migration ability of U87 cells by PGI/AMF siRNA. Wound healing capacity was significantly inhibited by $52.6 \%$ in the cells transfected with PGI/AMF siRNA compared with those transfected with scrambled siRNA $(\mathrm{P}<0.001)$ (Fig. 2A). The Transwell assay showed that the silencing of PGI/AMF with siRNA significantly decreased the number of migrating cells $(-80.4 \%$ vs. scrambled siRNA, $\mathrm{P}<0.001)$ (Fig. $2 \mathrm{~B})$. 


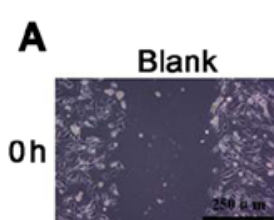

$8 \mathrm{~h}$
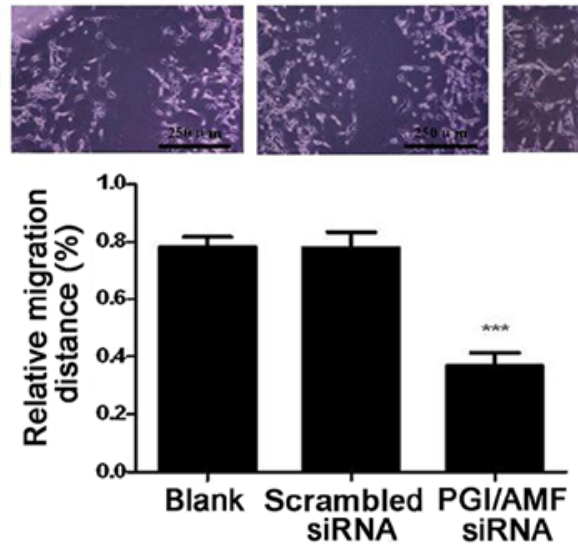

\section{Scrambled} SiRNA

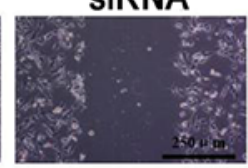

B
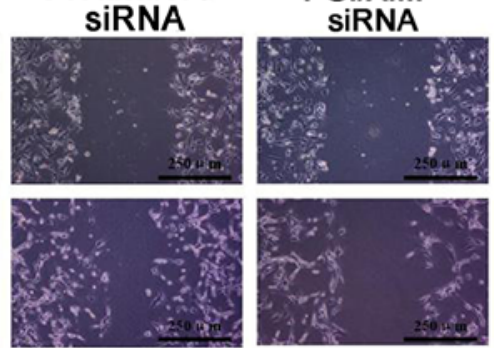

siRNA
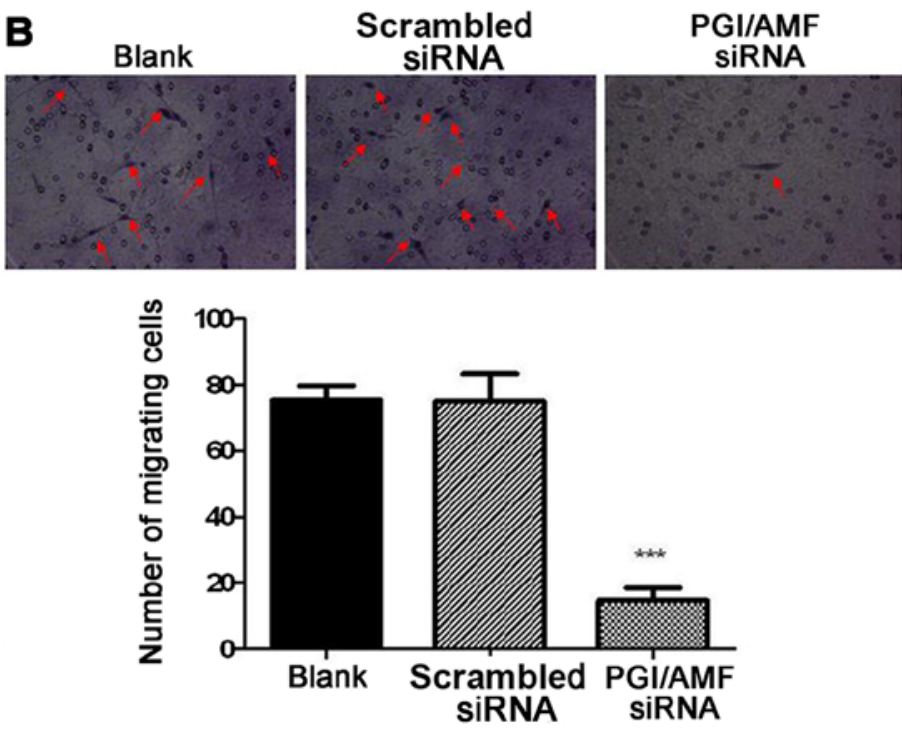

Figure 2. Effect of phosphoglucose isomerase/autocrine motility factor (PGI/AMF) silencing on U87 cell migration. The U87 cells were transfected with PGI/AMF siRNA or scrambled siRNA for $72 \mathrm{~h}$. (A) Migration was determined by a monolayer wound healing assay. A line was scratched with a $200-\mu 1$ plastic pipette tip. The cells were allowed to grow at $37^{\circ} \mathrm{C}$ in an atmosphere with $5 \% \mathrm{CO}_{2}$. After $8 \mathrm{~h}$, images of the cells that had migrated to the wounded areas were captured under a microscope for quantification of cell migration. Scale bar, $250 \mu \mathrm{m}$. (B) Migration was determined using a Transwell migration assay. After incubation at $37^{\circ} \mathrm{C}$ for $8 \mathrm{~h}$, the cells (red arrows) that had migrated to the lower surface of the membrane were fixed and stained with $1 \% \mathrm{H} \& \mathrm{E}$ (magnification, $\mathrm{x} 100)$. Data are represented as the means $\pm \mathrm{SD}$ from three independent experiments. ${ }^{* * *} \mathrm{P}<0.001$ vs. scrambled siRNA.
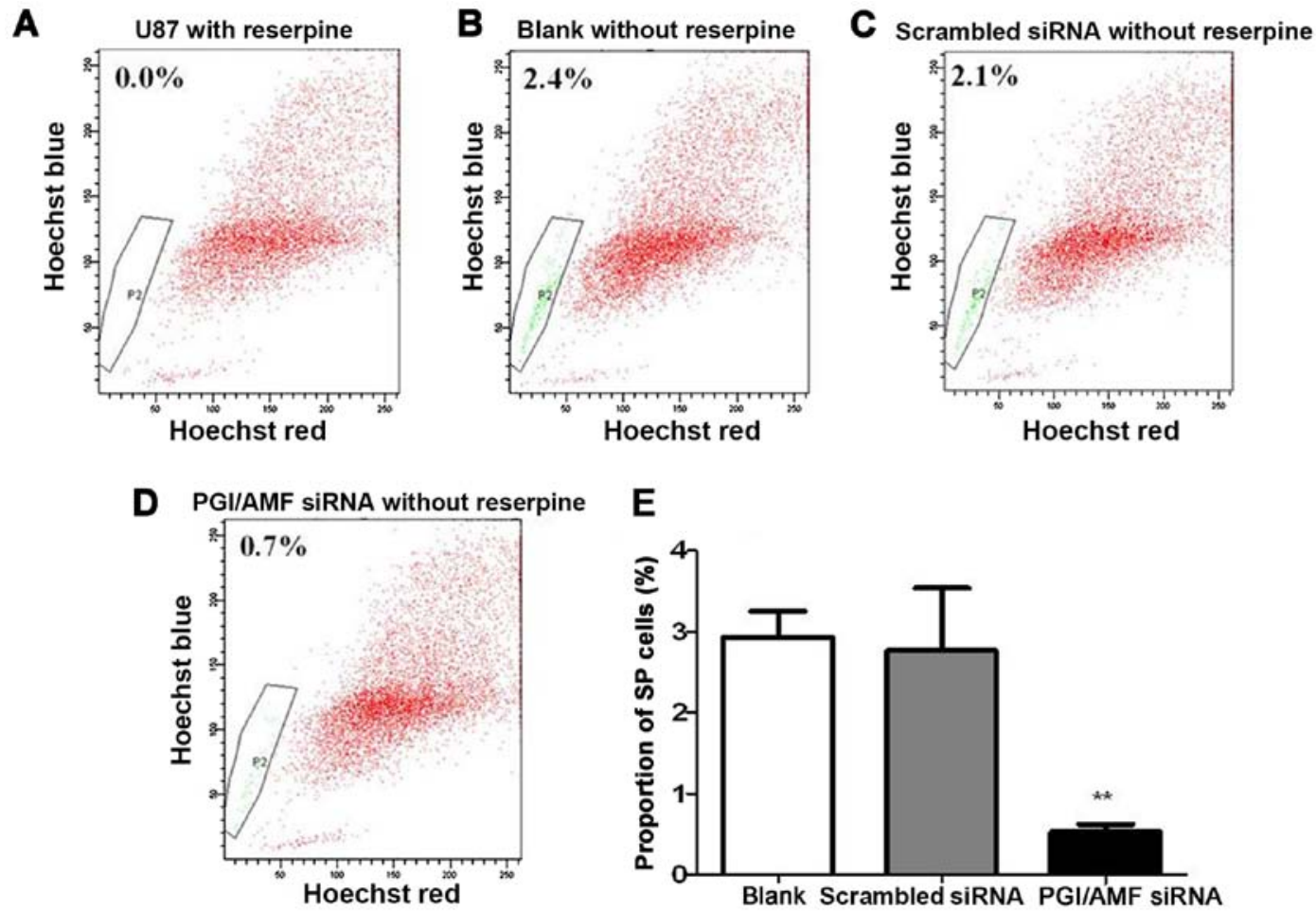

Figure 3. Effect of phosphoglucose isomerase/autocrine motility factor (PGI/AMF) silencing on side population cell (SPC) phenotype in U87 cells. U87 cells were transfected with PGI/AMF siRNA or scrambled siRNA for $72 \mathrm{~h}$, and then stained with $5 \mu \mathrm{g} / \mathrm{ml} \mathrm{Hoechst} 33342$ dye. (A) U87 cells treated with reserpine (50 $\mu \mathrm{mol} / \mathrm{l})$ were included during the entire staining procedure as controls for SPC gating. (B) U87 cells or (C) U87 cells transfected with scrambled siRNA or (D) PGI/AMF siRNA were stained with Hoechst 33342 dye in the absence of reserpine. The SPC phenotype was analyzed by flow cytometry. P2, Proportion of SPCs (\%). (E) Proportion of SPCs (\%). Data are represented as the means \pm SD of at least three independent experiments. ${ }^{* *} \mathrm{P}<0.01$ vs. scrambled siRNA.

Silencing of PGI/AMF reduces the ratio of SPCs. As shown in Figure 3, flow cytometric analysis revealed that the proportion of SPCs was decreased by $80.7 \%$ or decreased to $19.3 \%$ in cells transfected with PGI/AMF siRNA compared with those which had been transfected with scrambled siRNA, $72 \mathrm{~h}$ after silencing of PGI/AMF (P<0.01) (Fig. 3). 


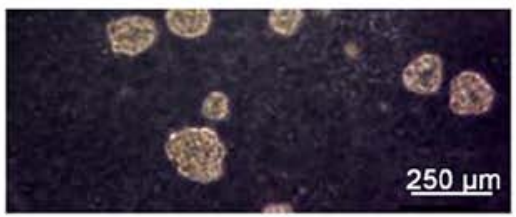

Blank

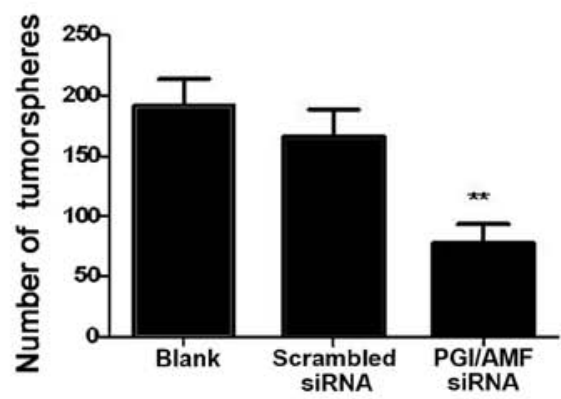

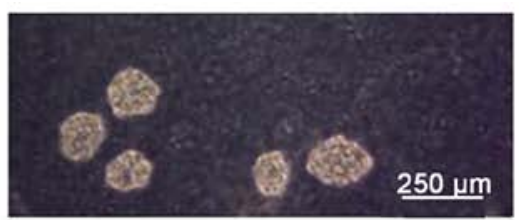

Scrambled siRNA

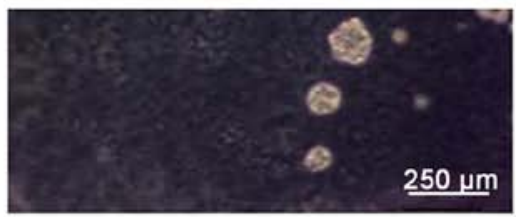

PGI/AMF SIRNA

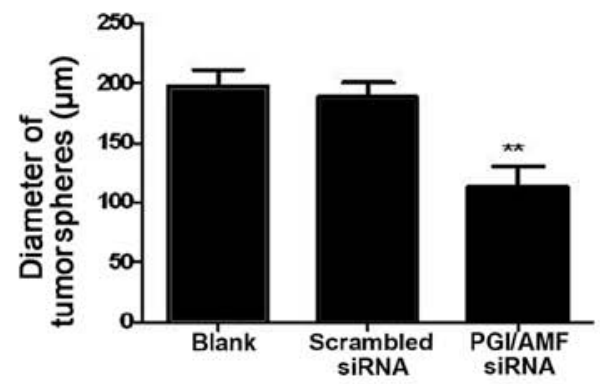

Figure 4. Silencing of phosphoglucose isomerase/autocrine motility factor (PGI/AMF) reduces the ability of U87 cells to form tumorspheres. The U87 cells were transfected with PGI/AMF siRNA or scrambled siRNA. After transfection (72 h), U87 cells (100 cells/well) were plated in 96-well plates, and $25 \mu \mathrm{l}$ of serum-free growth medium was added every day for 14 days. After 14 days, the diameter of the tumorspheres was measured and those $>100 \mu \mathrm{m}$ were counted as tumorsphere-forming units. Spheres were counted and measured from 32 different wells/experiment. Scale bar, $250 \mu \mathrm{m}$. The mean number and diameter $(\mu \mathrm{m})$ of tumorspheres was determined. Data are represented as the means $\pm \mathrm{SD}$ from three independent experiments. ${ }^{* *} \mathrm{P}<0.01$ vs. scrambled siRNA.

Silencing of PGI/AMF reduces tumorsphere formation. The U87 cells transfected with PGI/AMF siRNA formed 53.1\% fewer tumorspheres compared with the control cells transfected with scrambled siRNA ( $\mathrm{P}<0.01)$ (Fig. 4). In addition, the size of the tumorspheres was significantly reduced in the cells transfected with PGI/AMF siRNA compared with the control cells $(113.0 \pm 17.3$ vs. $197.3 \pm 14.0$ and $188.0 \pm 12.3 \mu \mathrm{m}$, $\mathrm{P}<0.01$ ) (Fig. 4).

Silencing of PGI/AMF decreases the phosphorylation level of Akt and the expression of SOX 2 in U87 cells. Akt expression levels were similar in the U87 cells transfected with PGI/AMF siRNA and in the control cells (both $\mathrm{P}>0.05$ ). However, the levels of p-Akt were markedly decreased $(-71.9 \%$, $\mathrm{P}<0.001$ ) (Fig. 5A). SOX2 levels were also significantly decreased in the cells transfected with PGI/AMF siRNA compared with scrambled siRNA $(-61.7 \%, \mathrm{P}<0.01)$ (Fig. 5B).

\section{Discussion}

PGI/AMF has been reported to regulate the proliferation and the survival of cells, and to prevent stress-induced apoptosis of tumor cells $(15,17,20)$. In the present study, silencing of PGI/AMF inhibited the migration ability of the glioblastoma U87 cells, decreased the proportion of SPCs, decreased sphere formation ability, and decreased the levels of p-Akt and the stemness marker, SOX2.

Previous research has shown that adult stem cells can be identified by an SPC phenotype. The SPCs, first described by Goodell et al (23), are a small subpopulation of cells presenting with enriched stem cell activity and a distinctively low Hoechst 33342 dye-staining pattern. Subsquent studies attributed this phenotype to the expression of ATP-binding cassette sub-family G member 2 (ABCG2), an ATP-binding cassette (ABC) transporter (24). Other studies have demonstrated the presence of SPCs in human cancers of different origins including acute myelogenous leukemia, neuroblastoma
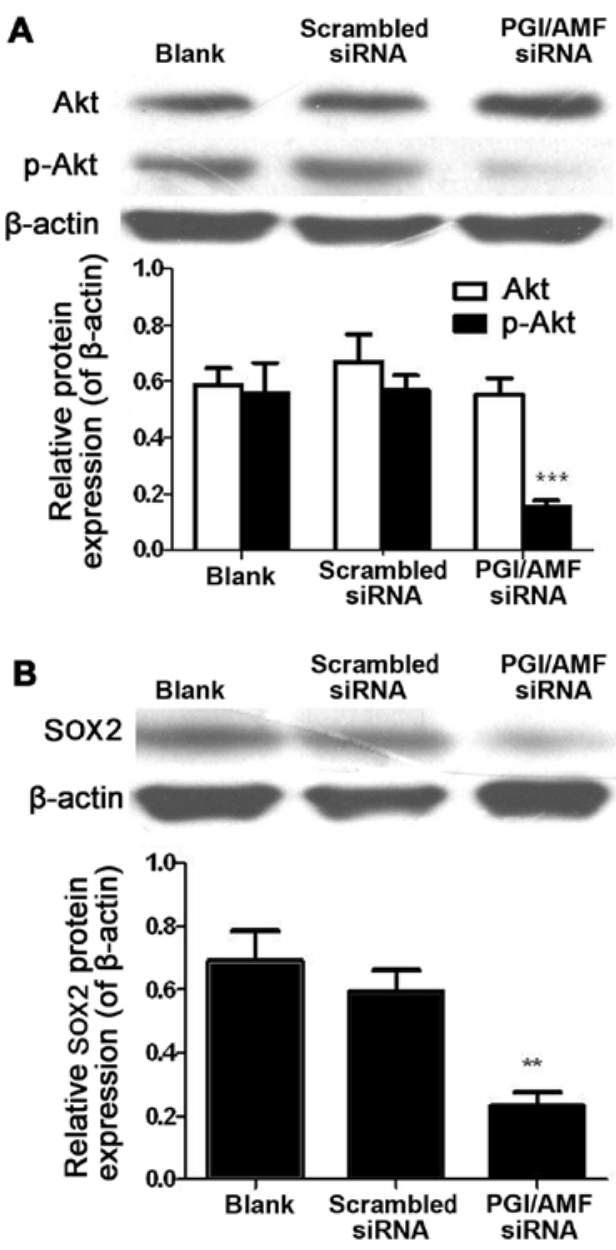

Figure 5. Effects of phosphoglucose isomerase/autocrine motility factor (PGI/AMF) silencing on the expression of Akt, p-Akt and SRY (sex determining region Y)-box 2 (SOX2) in U87 cells. U87 cells were transfected with PGI/AMF siRNA or scrambled siRNA for $72 \mathrm{~h}$. The protein expression of (A) Akt and p-Akt, and (B) SOX2 was determined by western blot analysis. $\beta$-actin was used as an internal control. Data are represented as the means \pm SD from three independent experiments. ${ }^{* *} \mathrm{P}<0.01$ and ${ }^{* * *} \mathrm{P}<0.001$ vs. scrambled siRNA. 
and glioma (21,25-27). SPCs are of great clinical significance. Indeed, previous research has shown that these cells are resistant to many drugs (25), contributing to the resistance of tumors to chemotherapy. Thus, decreasing the proportion of SPCs within tumors is a viable option for improving the effectiveness of chemotherapy, particularly in aggressive tumors such as glioblastomas. The present study suggests that silencing PGI/AMF is a way to decrease the proportion of SPCs in glioblastomas.

It is now widely accepted that tumors contain a mixed population of cells at various stages of differentiation, of which only a fraction can perpetuate the tumor; these cells are named cancer stem cells $(28,29)$. However, given the impossibility of directly identifying them due to a lack of specific markers, these cells are operationally defined as the small fraction of cancer cells that have the ability to propagate the tumor upon transplantation into immunodeficient mice $(28,29)$. The xenotransplanted tumor may be serially transplanted into new recipient mice, highlighting the capacity for perpetual self-renewal of this subset of cancer cells. These cells share genetic and phenotypic features with normal neural stem cells such as the expression of the transcription factor, SOX2 $(30,31)$. SOX 2 plays an essential role in maintaining the proliferative potential of neural stem/precursor cells and in ensuring the production of sufficient cell numbers of the appropriate type (32-34). The results of the present study demonstrated that silencing of PGI/AMF decreased the expression of SOX2, suggesting that PGI/AMF signaling is involved in cancer stem cell proliferation and malignant functions.

The serine/threonine kinase, Akt/protein kinase B pathway is a nodal point regulating a number of tumor-associated processes, including cell growth, cell cycle progression, survival, migration and angiogenesis, and has been shown to be important in many malignancies including glioblastoma (17,3537). More specifically, the Akt pathway has been shown to be activated in the majority of glioblastoma multiforme tumors $(35,36)$. In other research, activation of the Akt pathway in a human astrocytic model of glioma resulted in the conversion of anaplastic astrocytoma to glioblastoma multiforme (37). In the present study, although the total expression level of Akt was almost unchanged in the silenced PGI/AMF cells compared with the control cells, the p-Akt level was decreased. These results are supported by a previous study showing that the overexpression of PGI/AMF in NIH-3T3 fibroblasts led to an accumulation of cellular p-Akt protein (17). These changes may have led to the reduced aggressiveness of the cells treated with silenced PGI/AMF. However, the present study did not explore the causal relationship between PGI/AMF silencing and the Akt pathway. More studies are necessary to correctly establish the chain of events.

In conclusion, the silencing of PGI/AMF decreases migration, tumorsphere formation and the proportion of side population cells in glioblastoma U87 cells. We suggest that the Akt pathway is involved. These results provide a potential new target for the treatment of glioblastoma.

\section{References}

1. Brandes AA, Tosoni A, Franceschi E, Reni M, Gatta G and Vecht C: Glioblastoma in adults. Crit Rev Oncol Hematol 67: 139-152, 2008.
2. Stupp R, Brada M, van den Bent MJ, Tonn JC, Pentheroudakis G and Group EGW; ESMO Guidelines Working Group: High-grade glioma: ESMO Clinical Practice Guidelines for diagnosis, treatment and follow-up. Ann Oncol 25 (Suppl 3): iii93-iii101, 2014.

3. Sanai N, Alvarez-Buylla A and Berger MS: Neural stem cells and the origin of gliomas. N Engl J Med 353: 811-822, 2005.

4. Yadav AK, Renfrow JJ, Scholtens DM, Xie H, Duran GE, Bredel C, Vogel H, Chandler JP, Chakravarti A, Robe PA, et al: Monosomy of chromosome 10 associated with dysregulation of epidermal growth factor signaling in glioblastomas. JAMA 302: 276-289, 2009.

5. Wen PY and Kesari S: Malignant gliomas in adults. N Engl J Med 359: 492-507, 2008.

6. Stupp R, Hegi ME, Mason WP, van den Bent MJ, Taphoorn MJ, Janzer RC, Ludwin SK, Allgeier A, Fisher B, Belanger K, et al; European Organisation for Research and Treatment of Cancer Brain Tumour and Radiation Oncology Groups; National Cancer Institute of Canada Clinical Trials Group: Effects of radiotherapy with concomitant and adjuvant temozolomide versus radiotherapy alone on survival in glioblastoma in a randomised phase III study: 5-year analysis of the EORTC-NCIC trial. Lancet Oncol 10: 459-466, 2009.

7. Tanizaki Y, Sato Y, Oka H, Utsuki S, Kondo K, Miyajima Y, Nagashio R and Fujii K: Expression of autocrine motility factor mRNA is a poor prognostic factor in high-grade astrocytoma. Pathol Int 56: 510-515, 2006.

8. Watanabe H, Takehana K, Date M, Shinozaki T and Raz A: Tumor cell autocrine motility factor is the neuroleukin/phosphohexose isomerase polypeptide. Cancer Res 56: 2960-2963, 1996.

9. Niinaka Y, Paku S, Haga A, Watanabe $\mathrm{H}$ and Raz A: Expression and secretion of neuroleukin/phosphohexose isomerase/maturation factor as autocrine motility factor by tumor cells. Cancer Res 58: 2667-2674, 1998.

10. Haga A, Niinaka Y and Raz A: Phosphohexose isomerase/ autocrine motility factor/neuroleukin/maturation factor is a multifunctional phosphoprotein. Biochim Biophys Acta 1480: 235-244, 2000.

11. Shimizu K, Tani M, Watanabe H, Nagamachi Y, Niinaka Y, Shiroishi T, Ohwada S, Raz A and Yokota J: The autocrine motility factor receptor gene encodes a novel type of seven transmembrane protein. FEBS Lett 456: 295-300, 1999.

12. Funasaka T, Haga A, Raz A and Nagase H: Tumor autocrine motility factor is an angiogenic factor that stimulates endothelial cell motility. Biochem Biophys Res Commun 285: 118-128, 2001.

13. Funasaka T, Haga A, Raz A and Nagase H: Autocrine motility factor secreted by tumor cells upregulates vascular endothelial growth factor receptor (Flt-1) expression in endothelial cells. Int J Cancer 101: 217-223, 2002.

14. Funasaka T, Haga A, Raz A and Nagase H: Tumor autocrine motility factor induces hyperpermeability of endothelial and mesothelial cells leading to accumulation of ascites fluid. Biochem Biophys Res Commun 293: 192-200, 2002.

15. Haga A, Funasaka T, Niinaka Y, Raz A and Nagase H: Autocrine motility factor signaling induces tumor apoptotic resistance by regulations Apaf-1 and Caspase-9 apoptosome expression. Int $\mathbf{J}$ Cancer 107: 707-714, 2003.

16. Romagnoli A, Oliverio S, Evangelisti C, Iannicola C, Ippolito G and Piacentini M: Neuroleukin inhibition sensitises neuronal cells to caspase-dependent apoptosis. Biochem Biophys Res Commun 302: 448-453, 2003.

17. Tsutsumi S, Hogan V, Nabi IR and Raz A: Overexpression of the autocrine motility factor/phosphoglucose isomerase induces transformation and survival of NIH-3T3 fibroblasts. Cancer Res 63: 242-249, 2003.

18. Tsutsumi S, Yanagawa T, Shimura T, Fukumori T, Hogan V, Kuwano H and Raz A: Regulation of cell proliferation by autocrine motility factor/phosphoglucose isomerase signaling. J Biol Chem 278: 32165-32172, 2003.

19. Yu FL, Liao MH, Lee JW and Shih WL: Induction of hepatoma cells migration by phosphoglucose isomerase/autocrine motility factor through the upregulation of matrix metalloproteinase-3. Biochem Biophys Res Commun 314: 76-82, 2004.

20. Funasaka T, Hu H, Yanagawa T, Hogan V and Raz A: Downregulation of phosphoglucose isomerase/autocrine motility factor results in mesenchymal-to-epithelial transition of human lung fibrosarcoma cells. Cancer Res 67: 4236-4243, 2007.

21. Feuring-Buske M and Hogge DE: Hoechst 33342 efflux identifies a subpopulation of cy togenetically normal $\mathrm{CD} 34^{+} \mathrm{CD} 38^{-}$progenitor cells from patients with acute myeloid leukemia. Blood 97: 3882-3889, 2001. 
22. Kim MC, D'Costa S, Suter S and Kim Y: Evaluation of a side population of canine lymphoma cells using Hoechst 33342 dye. J Vet Sci 14: 481-486, 2013.

23. Goodell MA, Brose K, Paradis G, Conner AS and Mulligan RC: Isolation and functional properties of murine hematopoietic stem cells that are replicating in vivo. J Exp Med 183: 1797-1806, 1996.

24. Zhou S, Schuetz JD, Bunting KD, Colapietro AM, Sampath J, Morris JJ, Lagutina I, Grosveld GC, Osawa M, Nakauchi H and Sorrentino BP: The ABC transporter Bcrp1/ABCG2 is expressed in a wide variety of stem cells and is a molecular determinant of the side-population phenotype. Nat Med 7: 1028-1034, 2001.

25. Hirschmann-Jax C, Foster AE, Wulf GG, Nuchtern JG, Jax TW, Gobel U, Goodell MA and Brenner MK: A distinct 'side population' of cells with high drug efflux capacity in human tumor cells. Proc Natl Acad Sci USA 101: 14228-14233, 2004.

26. Kondo T, Setoguchi T and Taga T: Persistence of a small subpopulation of cancer stem-like cells in the C6 glioma cell line. Proc Natl Acad Sci USA 101: 781-786, 2004.

27. Wulf GG, Wang RY, Kuehnle I, Weidner D, Marini F, Brenner MK, Andreeff M and Goodell MA: A leukemic stem cell with intrinsic drug efflux capacity in acute myeloid leukemia. Blood 98: 1166-1173, 2001.

28. Vermeulen L, Sprick MR, Kemper K, Stassi G and Medema JP Cancer stem cells - old concepts, new insights. Cell Death Differ 15: 947-958, 2008

29. Singh SK, Clarke ID, Terasaki M, Bonn VE, Hawkins C, Squire J and Dirks PB: Identification of a cancer stem cell in human brain tumors. Cancer Res 63: 5821-5828, 2003.

30. Boumahdi S, Driessens G, Lapouge G, Rorive S, Nassar D, Le Mercier M, Delatte B, Caauwe A, Lenglez S, Nkusi E, et al: SOX2 controls tumour initiation and cancer stem-cell functions in squamous-cell carcinoma. Nature 511: 246-250, 2014.
31. Brafman DA, Moya N, Allen-Soltero S, Fellner T, Robinson M, McMillen ZL, Gaasterland T and Willert K: Analysis of SOX2-expressing cell populations derived from human pluripotent stem cells. Stem Cell Rep 1: 464-478, 2013.

32. Bani-Yaghoub M, Tremblay RG, Lei JX, Zhang D, Zurakowski B, Sandhu JK, Smith B, Ribecco-Lutkiewicz M, Kennedy J, Walker PR, et al: Role of Sox 2 in the development of the mouse neocortex. Dev Biol 295: 52-66, 2006.

33. Ferri AL, Cavallaro M, Braida D, Di Cristofano A, Canta A, Vezzani A, Ottolenghi S, Pandolfi PP, Sala M, DeBiasi S and Nicolis SK: Sox 2 deficiency causes neurodegeneration and impaired neurogenesis in the adult mouse brain. Development 131: 3805-3819, 2004.

34. Graham V, Khudyakov J, Ellis P and Pevny L: SOX2 functions to maintain neural progenitor identity. Neuron 39: 749-765, 2003.

35. Holland EC, Celestino J, Dai C, Schaefer L, Sawaya RE and Fuller GN: Combined activation of Ras and Akt in neural progenitors induces glioblastoma formation in mice. Nat Genet 25: 55-57, 2000.

36. Rajasekhar VK, Viale A, Socci ND, Wiedmann M, Hu X and Holland EC: Oncogenic Ras and Akt signaling contribute to glioblastoma formation by differential recruitment of existing mRNAs to polysomes. Mol Cell 12: 889-901, 2003.

37. Sonoda Y, Ozawa T, Aldape KD, Deen DF, Berger MS and Pieper RO: Akt pathway activation converts anaplastic astrocytoma to glioblastoma multiforme in a human astrocyte model of glioma. Cancer Res 61: 6674-6678, 2001. 